\title{
The Relationship between the Number of Manic Episodes and Oxidative Stress Indicators in Bipolar Disorder
}

\author{
Süleyman Akarsu ${ }^{\circledR}$, Abdullah Bolu², Emre Aydemir ${ }^{3}$, Selma Bozkurt Zincir, \\ Yasemin Gülcan Kurt ${ }^{5}$, Serkan Zincir ${ }^{6}$, Murat Erdem ${ }^{7}$, and Özcan Uzun ${ }^{2}$ \\ ${ }^{1}$ Department of Psychiatry, Freelance Physician, Hatay, Turkey \\ 2Department of Psychiatry, Gülhane Education and Research Hospital, Ankara, Turkey \\ ${ }^{3}$ Department of Psychiatry, Beytepe State Hospital, Ankara, Turkey \\ ${ }^{4}$ Department of Psychiatry, Medical Park Göztepe Hospital Complex, Istanbul, Turkey \\ ${ }^{5}$ Department of Biochemistry, Freelance Physician, Ankara, Turkey \\ ${ }^{6}$ Department of Psychiatry, Eskişehir State Hospital, Eskişehir, Turkey \\ ${ }^{7}$ Department of Psychiatry, Bilted Psychiatry Treatment Center, Ankara, Turkey
}

\begin{abstract}
Objective Bipolar disorder (BD) is a chronic mood disorder characterized by recurrent episodes that has a lifetime prevalence of $0.4-$ $5.5 \%$. The neurochemical mechanism of BD is not fully understood. Oxidative stress in neurons causes lipid peroxidation in proteins associated with neuronal membranes and intracellular enzymes and it may lead to dysfunction in neurotransmitter reuptake and enzyme activities. These pathological processes are thought to occur in brain regions associated with affective functions and emotions in BD. The relationship between the number of manic episodes and total oxidant-antioxidant capacity was investigated in this study.

Methods Eighty-two BD patients hospitalized due to manic symptoms and with no episodes of depression were enrolled in the study. Thirty of the 82 patients had had their first episode of mania, and the other 52 patients had had two or more manic episodes. The control group included 45 socio-demographically matched healthy individuals. Serum total antioxidant capacity (TAC) and total oxidant capacity (TOC) measurements of the participants were performed. The oxidative stress index (OSI) was calculated by TOC/TAC.

Results There were no significant differences in OSI scores between BD patients with first-episode mania and BD patients with more than one manic episode. However, OSI scores in both groups were significantly higher than in the control group. TOC levels of BD patients with first-episode mania were found to be significantly higher than TOC levels of BD patients with more than one manic episode and healthy controls. There were no significant differences in TAC levels between BD patients with first-episode mania and BD patients with more than one manic episode. TAC levels in both groups were significantly higher than in the control group.

Conclusion Significant changes in oxidative stress indicators were observed in this study, confirming previous studies. Increased levels of oxidants were shown with increased disease severity rather than with the number of manic episodes. Systematic studies, including of each period of the disorder, are needed for using the findings indicating deterioration of oxidative parameters.
\end{abstract}

Psychiatry Investig 2018;15(5):514-519

Key Words Oxidative stress, Manic episode, Bipolar disorder, Antioxidant

\section{INTRODUCTION}

Bipolar disorder (BD) is a chronic mood disorder characterized by recurrent episodes and has a lifetime prevalence of

Received: June 14, 2016 Revised: September 28, 2016

Accepted: December 31, 2016

$\square$ Correspondence: Süleyman Akarsu, MD

Department of Psychiatry, Freelance Physician, Numune District, 566. Street,

No: 4/8, 31200, Iskenderun, Hatay, Turkey

Tel: +90-530-7653032, Fax: +90-326-618 0808

E-mail: sakarsu82@gmail.com

(c) This is an Open Access article distributed under the terms of the Creative Commons Attribution Non-Commercial License (http://creativecommons.org/licenses/bync/4.0) which permits unrestricted non-commercial use, distribution, and reproduction in any medium, provided the original work is properly cited.
0.4-5.5\%. ${ }^{1}$ The neurochemical mechanism of $\mathrm{BD}$ is not fully understood. Postmortem studies demonstrated the involvement of mitochondrial dysfunction in the brains of $\mathrm{BD}$ patients, ${ }^{2-5}$ suggesting that mitochondrial dysfunction might be a pathophysiological mechanism in this disorder.

Reactive oxygen species (ROS) occur in the mitochondria and are potentially eliminated by antioxidant enzymes such as superoxide dismutase (SOD), catalase, and glutathione peroxidase. ${ }^{6}$ Disturbances between the antioxidant activity and ROS production causes oxidative stress in tissues. Oxidative stress can lead to lipid peroxidation in membranes, so impairment of signal transduction, structural plasticity, and cell flexibility 
can occur. All of these processes constitute neural injury. ${ }^{7,8}$ Although increased ROS may lead to mitochondrial damage, mitochondrial dysfunction may cause ROS production. ${ }^{9,10}$ The brain is particularly sensitive to oxidative stress because of the use of a large proportion of oxygen in the body, and the antioxidant capacity of the brain to tolerate oxidative stress is limited. ${ }^{11}$ Sensitivity of the brain to changes in oxidative metabolism and detection of an increasing number of neurodegenerative changes in neuropsychiatric disorders have led to the idea that oxidative damage is part of the etiology of neuropsychiatric diseases. ${ }^{12,13}$

Increases in lipid peroxidation, DNA and RNA damage, and nitric oxide (NO) levels in patients with BD compared to healthy control groups have been identified in a recent metaanalysis that assessed studies regarding the oxidative stress in $\mathrm{BD} .^{8}$ A possible mechanism of these effects generated by the oxidative stress in BD is not clear. Oxidative stress in neurons cause lipid peroxidation in proteins associated with neuronal membrane and intracellular enzymes. These pathological processes may lead to cell apoptosis and dysfunctions in neurotransmitter reuptake and enzyme activities and are thought to occur in brain regions associated with affective functions and emotions in BD. ${ }^{11,14-17}$

Although activation of oxidative stress and antioxidant mechanisms during a manic episode was observed, ${ }^{18}$ differences in terms of oxidative stress indicators between the firstepisode mania and recurrent manic episodes have been not examined. The relationship between the number of manic episodes and total oxidant-antioxidant capacity was investigated in this study.

\section{METHODS}

The study population consisted of BD with manic episode who were referred to the Department of Psychiatry of Gülhane Military Medical University, Turkey between 2011 and 2014. The study protocol was approved by the Ethics Committee with the number 1500-11, and all of the participants and their relatives provided written informed consent. BD patients with a history of depressive episodes were excluded from the study to provide homogeneity between the groups. Also, patients with comorbid psychiatric disorders, who were using antipsychotics, mood stabilizers, or any drugs in the past month, and those with medical conditions such as hypertension and diabetes, were excluded from the study.

Among the $125 \mathrm{BD}$ patients registered to the hospital, 82 BD patients hospitalized due to manic symptoms and with no episodes of depression were enrolled in the study. Thirty of the 82 patients had had only one manic episode, and the other 52 patients had had two or more manic episodes.
The BD patients with first-episode mania in the present study were drug naïve, but the BD patients with more than one manic episode had a history of mood stabilizer use. Positive history of drug use might have effects on oxidative stress. To minimize this possibility, the present study's BD patients with more than one manic episode did not use any drug for 4 weeks prior to beginning the study.

All the BD patients underwent a diagnostic interview, using the Structured Clinical Interview for DSM-IV Axis I Disorders (SCID-I), and disease severity was evaluated using the Young Mania Rating Scale (YMRS). ${ }^{19,20}$ The control group included 45 socio-demographically matched healthy individuals. Participants' demographic (age, gender, education level, and marital status) and clinical features were determined using a data collection form.

Blood samples of the patients and the control group were taken from the antecubital vein after 12 hours of fasting. Blood samples were centrifuged at $2000 \mathrm{rpm}$ for 10 minutes, and plasma was separated. Serum total antioxidant capacity (TAC) and total oxidant capacity (TOC) measurements were performed in a biochemistry laboratory, and the oxidative stress index (OSI) was calculated by TOC/TAC.

Total antioxidant capacity (TAC) is a method that measures the total antioxidant capacity of the body against powerful free radicals. ${ }^{21,22}$ Antioxidants' inhibition of color formation formed with oxidation reactions is measured spectrophotometrically in automatic analyzers. ${ }^{23}$ The TAC value is expressed as an equivalent of the millimolar concentration of Trolox solution. $^{24}$

Like antioxidant molecules, concentrations of different oxidant species can be measured separately, but this is not practical. ${ }^{25}$ Oxidation reactions in a sample form a colored compound associated with the amount of oxidant and are measured spectrophotometrically. The method developed can be used to measure the TOS of samples. ${ }^{25}$ The TOC value is expressed as $\mu \mathrm{mol} \mathrm{H}_{2} \mathrm{O}_{2}$ Eqv./L.

The oxidative stress index (OSI) was calculated by dividing the total oxidants status (TOS) by the total antioxidants status (TAS). ${ }^{26}$ OSI is used as a parameter for evaluation of the oxidative stress. ${ }^{12,22}$ Both antioxidant and oxidant sides of the oxidative metabolism may be assessed with OSI and antioxidants, and oxidants may be compared. ${ }^{22}$

Descriptive data are expressed as mean \pm SD (range). An ANOVA test was used for comparison of age, educational level, and oxidative stress indicators (TOC, TAC, and OSI) of the three groups. Post-hoc analyses were performed with the Tukey test. The chi-square test was used for comparison of marital status, gender, and smoking habits of the three groups. The comparison of YMRS scores of the patient groups were conducted using a t-test. The relationship of clinical variables to oxidative 
Table 1. Comparison of socio-demographic characteristics and oxidative capacity

\begin{tabular}{|c|c|c|c|c|c|}
\hline Variable & $\begin{array}{c}\text { BD patients } \\
\text { with first-episode } \\
\text { mania (I) } \\
(\mathrm{N}=30)\end{array}$ & $\begin{array}{c}\text { BD patients } \\
\text { with more than } \\
\text { one manic episode (II) } \\
(\mathrm{N}=52)\end{array}$ & $\begin{array}{l}\text { Healthy Controls } \\
\qquad \begin{array}{c}\text { (III) } \\
(\mathrm{N}=45)\end{array}\end{array}$ & Statistics & Comparison \\
\hline Age (year) & $22.7 \pm 2.6$ & $32.4 \pm 8.4$ & $29.7 \pm 5.6$ & $\mathrm{~F}=3.046, \mathrm{p}=0.065$ & \\
\hline Smoking (N, \%) & $26(87)$ & $36(69)$ & $23(51)$ & $\chi^{2 *}=0.840, \mathrm{p}=0.657$ & \\
\hline Education level (year) & $10.0 \pm 2.3$ & $10.5 \pm 2.8$ & $10.8 \pm 2.9$ & $\mathrm{~F}=0.146, \mathrm{p}=0.865$ & \\
\hline \multicolumn{6}{|l|}{ Gender (N, \%) } \\
\hline Female & $4(13)$ & $17(32)$ & $18(40)$ & $\chi^{2 *}=4.857, p=0.88$ & \\
\hline Male & $26(87)$ & $35(68)$ & $27(60)$ & & \\
\hline YMRS & $30.50 \pm 5.29$ & $28.02 \pm 4.23$ & - & $\mathrm{t}=2.308, \mathrm{p}=0.024$ & \\
\hline $\mathrm{TOC}\left(\mu \mathrm{mol} \mathrm{H} \mathrm{O}_{2} \mathrm{Eqv} / \mathrm{L}\right)$ & $24.22 \pm 7.88$ & $14.50 \pm 5.43$ & $4.04 \pm 3.00$ & $\mathrm{~F}=6.202, \mathrm{p}=0.003$ & $\mathrm{I}>\mathrm{II}>\mathrm{III}$ \\
\hline TAC ( $\mu$ mol Trolox Eqv/L) & $2.67 \pm 1.25$ & $2.08 \pm 0.46$ & $1.02 \pm 0.45$ & $\mathrm{~F}=10.928, \mathrm{p}=0.001$ & $\mathrm{I}=\mathrm{II}>\mathrm{III}$ \\
\hline OSI & $10.95 \pm 2.99$ & $7.76 \pm 2.32$ & $3.99 \pm 1.02$ & $\mathrm{~F}=5.112, \mathrm{p}=0.008$ & $\mathrm{I}=\mathrm{II}>\mathrm{III}$ \\
\hline
\end{tabular}

All data are presented as mean \pm SD or \%. F: ANOVA test value, t: Student $t$ test, ${ }^{*}$ chi-square test value. BD: bipolar disorder, YMRS: Young Mania Rating Scale, TOC: total oxidative capacity, TAC: total antioxidative capacity, OSI: oxidative stress index

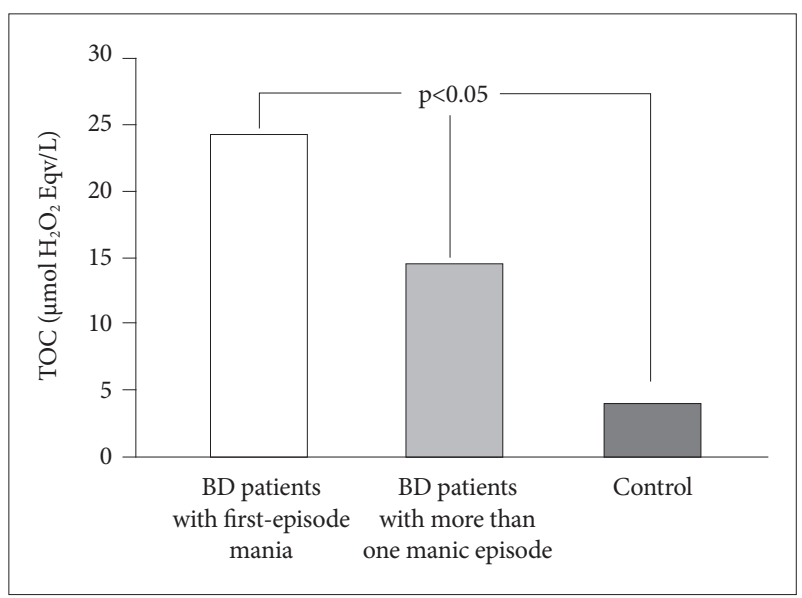

Figure 1. Comparisons of TOC levels between BD patients with first-episode mania, BD patients with more than one manic episode and control group. BD: bipolar disorder, TOC: total oxidative capacity.

stress indicators was measured by Pearson correlation analysis. The level of statistical significance was set at $\mathrm{p}<0.05$.

\section{RESULTS}

Sociodemographic characteristics (age, gender, smoking habits, marital status, and education level) did not differ significantly between the three groups (Table 1). Also, comparison of oxidative stress indicators (TOC, TAC, and OSI) between the three groups is shown in Table 1.

TOC levels were different in the three groups $(\mathrm{p}<0.05)$ (I> II $>$ III). TOC levels of BD patients with first-episode mania (24.22 $\pm 7.88 \mu \mathrm{mol} \mathrm{H}_{2} \mathrm{O}_{2}$ Eqv./L) were found to be significantly higher than TOC levels of $\mathrm{BD}$ patients who have had more

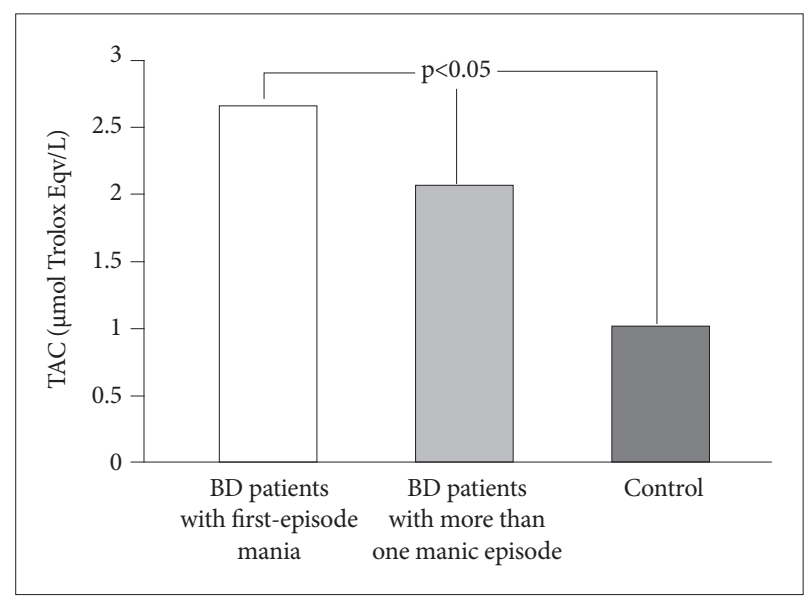

Figure 2. Comparisons of TAC levels between BD patients with first-episode mania, BD patients with more than one manic episode and control group. BD: bipolar disorder, TAC: total antioxidative capacity.

than one manic episode $\left(14.50 \pm 5.43 \mu \mathrm{mol} \mathrm{H}_{2} \mathrm{O}_{2}\right.$ Eqv./L) and healthy controls (4.04 $\pm 3.00 \mu \mathrm{mol} \mathrm{H}_{2} \mathrm{O}_{2} \mathrm{Eqv}$./L) (Figure 1).

There were no significant differences in TAC levels between BD patients with first-episode mania $(2.67 \pm 1.25 \mu$ mol Trolox Eqv./L) and $\mathrm{BD}$ patients with more than one manic episode $(2.08 \pm 0.46 \mu \mathrm{mol}$ Trolox Eqv./L) (p>0.05). However, TAC levels in both groups were significantly higher than in the control group $(1.02 \pm 0.45 \mu \mathrm{mol}$ Trolox Eqv./L) $(\mathrm{p}<0.05)$ (Figure 2) .

When the three groups were evaluated in terms of OSI score, there were no significant differences between $\mathrm{BD}$ patients with first-episode mania $(10.95 \pm 2.99)$ and $\mathrm{BD}$ patients with more than one manic episode $(7.76 \pm 2.32)$ ( $p>0.05)$. However, OSI scores in both groups were significantly higher than in the control group $(3.99 \pm 1.02)(\mathrm{p}<0.05)$ (Figure 3$)$. 




Figure 3. Comparisons of OSI scores between BD patients with first-episode mania, BD patients with more than one manic episode and control group. BD: bipolar disorder, TOC: total oxidative capacity, TAC: total antioxidative capacity, OSI: oxidative stress index.

No relationship was found between the number of manic episodes and TOC levels, TAC levels, and OSI scores of BD patients ( $p>0.05$ ). However, a positive correlation was found between YMRS scores of the BD patients and TOC levels ( $\mathrm{r}=$ $0.327)$ and OSI scores $(\mathrm{r}=0.300)(\mathrm{p}<0.05)$.

\section{DISCUSSION}

Increased oxidative stress indicators in bipolar disorder have been identified in previous studies. ${ }^{8,27}$ Savas et al. ${ }^{28}$ had determined higher NO levels in $\mathrm{BD}$ patients with manic episodes compared to their control group. TOC levels in both $\mathrm{BD}$ patients with first-episode mania and BD patients with more than one manic episode were found to be higher than the healthy control group in this study. The results showed that TOC levels were at the highest levels in BD patients with firstepisode mania. Although this elevation decreased in later episodes, it continued to remain at a higher level than in the control group.

Considering the neuroprotective effect of lithium, ${ }^{18,29}$ the use of mood stabilizers in previous manic episodes might explain the lower TOC levels of $\mathrm{BD}$ patients with more than one manic episode than the TOC levels in BD patients with firstepisode mania. Although increased oxidative stress levels were determined with increased duration of the disease in previous studies ${ }^{22,30}$ we found the highest oxidative stress levels in the first manic episode.

In euthymic episodes, disease duration seems to be decisive in terms of oxidative stress; therefore, oxidative stress increases if the disease process increases. However, in a manic episode, the history of previous episodes seems to be associated with relatively low levels of oxidative stress. Savas et al. ${ }^{31}$ found a positive relationship between $\mathrm{NO}$ level and the number of manic episodes in $27 \mathrm{BD}$ patients with euthymic episodes. Our results may differ from the results of Savas et al. because we performed the laboratory measurements during the manic episode.

We found no significant difference in TAC levels between $\mathrm{BD}$ patients with first-episode mania and BD patients with more than one manic episode. However, TAC levels in both groups were significantly higher than in the control group. This result may suggest that antioxidant mechanisms aggravated by exposure to oxidative stress maintained their high levels of activity regardless of the number of manic episodes.

TAC levels of the $\mathrm{BD}$ patients in euthymic episodes were not investigated in this study, but decreased oxidative stress and increased antioxidant capacity due to mood stabilizer treatment has been shown in previous studies. ${ }^{15,22,32}$ Antioxidant and neuroprotective effects of mood stabilizers such as lithium, valproic acid, lamotrigine, and carbamazepine have been demonstrated in various studies, ${ }^{33-40}$ as have the enhancing effects of lithium, valproate, lamotrigine, and carbamazepine on the brain-derived neurotrophic factor (BDNF). ${ }^{41,42}$ Both lithium and valproic acid have been shown to increase expression of the major neuroprotective protein bcl- $2 .{ }^{15}$ Lithium caused a decline in the SOD/catalase rate in healthy subjects. ${ }^{29}$ Lithium seems to exert antioxidant effects during mania. ${ }^{18}$

In a study about TAC levels in $\mathrm{BD}$ patients, TAC levels were found to be higher in $\mathrm{BD}$ patients with euthymic episodes than in a control group. ${ }^{22}$ These results were consistent with the results of higher TAC levels in $\mathrm{BD}$ patients compared to the control group in our study; however, a negative correlation was found between the number of episodes and TAC levels in BD type I patients in the same study. ${ }^{22}$ Although BD patients were not separated into type I and II in our study, the finding of no relationship between number of manic episodes and TAC levels was not consistent with the Yumru et al..$^{22}$ study. Mood stabilizers used by the patient in the study by Yumru et al..$^{22}$ likely were the most important reason for this discrepancy. The other reason might be the lack of homogeneity of our patients in terms of their episodes.

No relationship was found between the number of manic episodes and TOC levels, TAC levels, and OSI scores of BD patients. Consistent with our findings, Savas et al. ${ }^{31}$ found no relationship between antioxidant enzyme SOD activity and the number of manic episodes in euthymic BD patients.

That the patient population is predominantly male could be considered a limitation. Also, BD patients with more than one manic episode had a treatment history, although they did not use any drug for 4 weeks prior to beginning the study. We could not clearly demonstrate the effect of treatment on oxidative stress parameters. Factors such as lifestyle and dietary patterns of the patients can affect the parameters of oxidative 
stress. Another limitation of this study is the small number of subjects who participated.

Significant changes in the oxidative stress indicators were observed in this study, confirming previous studies. Increased levels of oxidants were observed with increased disease severity rather than according to the number of manic episodes. Regular monitoring of the disease periods and recording of changes in oxidative parameters in the process, comparison of oxidative parameters of patients receiving and not receiving treatment, examination of oxidative parameters of patients in different episodes (such as manic, depressive, or euthymic episodes), and identification of differences between subtypes of $\mathrm{BD}$ required to must be performed to identify the dysfunctions associated with the oxidative system as a characteristic property of the disorder.

\section{REFERENCES}

1. Morgan VA, Mitchell PB, Jablensky AV. The epidemiology of bipolar disorder: sociodemographic, disability and service utilization data from the Australian National Study of Low Prevalence (Psychotic) Disorders. Bipolar Disord 2005;7:326-337.

2. Sun X, Wang JF, Tseng M, Young LT. Downregulation in components of the mitochondrial electron transport chain in the postmortem frontal cortex of subjects with bipolar disorder. J Psychiatry Neurosci 2006; 31:189-196.

3. MacDonald ML, Naydenov A, Chu M, Matzilevich D, Konradi C. Decrease in creatine kinase messenger RNA expression in the hippocampus and dorsolateral prefrontal cortex in bipolar disorder. Bipolar Disord 2006;8:255-264.

4. Iwamoto K, Bundo M, Kato T. Altered expression of mitochondria-related genes in postmortem brains of patients with bipolar disorder or schizophrenia, as revealed by large-scale DNA microarray analysis. Hum Mol Genet 2005;14:241-253.

5. Konradi C, Eaton M, MacDonald ML, Walsh J, Benes FM, Heckers S. Molecular evidence for mitochondrial dysfunction in bipolar disorder. Arch Gen Psychiatry 2004;61:300-308.

6. Adam-Vizi V, Chinopoulos C. Bioenergetics and the formation of mitochondrial reactive oxygen species. Trends Pharmacol Sci 2006;27: 639-645.

7. Takuma K, Baba A, Matsuda T. Astrocyte apoptosis: implications for neuroprotection. Prog Neurobiol 2004;72:111-127.

8. Brown NC, Andreazza AC, Young LT. An updated meta-analysis of oxidative stress markers in bipolar disorder. Psychiatry Res 2014;218: 61-68.

9. Serrano F, Klann E. Reactive oxygen species and synaptic plasticity in the aging hippocampus. Ageing Res Rev 2004;3:431-443.

10. Kunz M, Gama CS, Andreazza AC, Salvador M, Ceresér KM, Gomes FA, et al. Elevated serum superoxide dismutase and thiobarbituric acid reactive substances in different phases of bipolar disorder and in schizophrenia. Prog Neuropsychopharmacol Biol Psychiatry 2008;32:16771681.

11. Berk M, Kapczinskie F, Andreazzae AC, Deana OM, Giorlando F, Maesg M, et al. Pathways underlying neuroprogression in bipolar disorder: Focus on inflammation, oxidative stress and neurotrophic factors. Neurosci Biobehav Rev 2011;35:804-817.

12. Kuloğlu M, Ustundag B, Atmaca M, Canatan H, Tezcan E, Cinkilinc N. Lipid peroxidation and antioxidant enzyme levels in patients with schizophrenia and bipolar disorder. Cell Biochem Funct 2002;20:171175 .
13. Ranjekar PK, Hinge A, Hegde MV, Ghate M, Kale A, Sitasawad S, et al. Decreased antioxidant enzymes and membrane essential polyunsaturated fatty acids in schizophrenic and bipolar mood disorder patients. Psychiatry Res 2003;121:109-122.

14. Erdem M, Akarsu S, Pan E, Kurt YG. Bipolar disorder and oxidative stress. J Mood Disord 2014;4:70-79.

15. Ozcan ME, Gulec M, Ozerol E, Polat R, Akyol O. Antioxidant enzyme activities and oxidative stress in affective disorders. Int Clin Psychopharmacol 2004;19:89-95.

16. Zarate CA, Singh J Jr, Manji HK. Cellular plasticity cascades: targets for the development of novel therapeutics for bipolar disorder. Biol Psychiatry 2006;59:1006-1020.

17. Akarsu S, Torun D, Erdem M, Kozan S, Akar H, Uzun O. Mitochondrial complex I and III mRNA levels in bipolar disorder. J Affect Disord 2015;184:160-163.

18. Machado-Vieira R, Andreazza AC, Viale CI, Zanatto V, Cereser Jr V, Vargas RS, et al. Oxidative stress parameters in unmedicated and treated bipolar subjects during initial manic episode: a possible role for lithium antioxidant effects. Neurosci Lett 2007;421:33-36.

19. Young RC, Biggs JT, Ziegler VE, Meyer DA. A rating scale for mania: reliability, validity and sensitivity. Br J Psychiatry 1978;133:429-435.

20. Karadağ F, Oral T, Yalçin FA, Erten E. Reliability and validity of Turkish translation of young mania rating scale. Turk Psikiyatri Derg 2002;13: 107-114.

21. Erel O. A novel automated method to measure total antioxidant response against potent free radical reactions. Clin Biochem 2004;37:112119.

22. Yumru M, Savas H, Kalenderoglu A, Bulut M, Celik H, Erel O. Oxidative imbalance in bipolar disorder subtypes: a comparative study. Prog Neuropsychopharmacol Biol Psychiatry 2009;33:1070-1074.

23. Erel O. A novel automated direct measurement method for total antioxidant capacity using a new generation, more stable ABTS radical cation. Clin Biochem 2004;37:277-285.

24. Prior RL, Cao G. In vivo total antioxidant capacity: comparison of different analytical methods. Free Radic Biol Med 1999;27:1173- 1181.

25. Erel O. A new automated colorimetric method for measuring total oxidant status. Clin Biochem 2005;38:1103-1111.

26. Kosecik M, Erel O, Sevinc E, Selek S. Increased oxidative stress in children exposed to passive smoking. Int J Cardiol 2005;100:61-64.

27. Andreazza AC, Kauer-Santanna M, Frey BN, Bond DJ, Kapczinski F, Young LT, et al. Oxidative stress markers in bipolar disorder: a metaanalysis. J Affect Disord 2008;111:135-144.

28. Savas HA, Herken H, Yürekli M, Uz E, Tutkun H, Zoroğlu SS, et al. Possible role of nitric oxide and adrenomedullin in bipolar disorder. Neuropsychobiology 2002;45:57-61.

29. Khairova R, Pawar R, Salvadore G, Juruena MF, De Sousa RT, SoeiroDe-Souza MG, et al. Effects of lithium on oxidative stress parameters in healthy subjects. Mol Med Report 2012;5:680-682.

30. Andreazza AC, Cassini C, Rosa AR, Leite MC, Almeida LMV, Nardin P, et al. Serum S100B and antioxidant enzymes in bipolar patients. J Psychiatr Res 2007;41:523-529.

31. Savas HA, Gergerlioglu HS, Armutcu F, Herken H, Yilmaz HR, Kocoglu E, et al. Elevated serum nitric oxide and superoxide dismutase in euthymic bipolar patients: impact of past episodes. World J Biol Psychiatry 2006;7:51-55.

32. Gergerlioglu HS, Savas HA, Bulbul F, Selek S, Uz E, Yumru M. Changes in nitric oxide level and superoxide dismutase activity during antimanic treatment. Prog Neuropsychopharmacol Biol Psychiatry 2007;31:697-702.

33. Frey BN, Valvassori SS, Reus GZ, Martins MR, Petronilho FC, Bardini $\mathrm{K}$, et al. Effects of lithium and valproate on amphetamine-induced oxidative stress generation in an animal model of mania. J Psychiatry Neurosci 2006;31:326-332.

34. Wang JF, Azzam JE, Young LT. Valproate inhibits oxidative damage to lipid and protein in primary cultured rat cerebrocortical cells. Neuro- 
science 2003;116:485-489.

35. Shao L, Young LT, Wang JF. Chronic treatment with mood stabilizers lithium and valproate prevents excitotoxicity by inhibiting oxidative stress in rat cerebral cortical cells. Biol Psychiatry 2005;58:879-884.

36. Chen B, Wang JF, Young LT. Chronic valproate treatment increases expression of endoplasmic reticulum stress proteins in the rat cerebral cortex and hippocampus. Biol Psychiatry 2000;48:658-664.

37. Shao L, Sun X, Xu L, Young LT, Wang JF. Mood stabilizing drug lithium increases expression of endoplasmic reticulum stress proteins in primary cultured rat cerebral cortical cells. Life Sci 2006;78:1317-1323.

38. Chen G, Zeng WZ, Yuan PX, Huang LD, Jiang YM, Zhao ZH, et al. The mood-stabilizing agents lithium and valproate robustly increase the levels of the neuroprotective protein bcl-2 in the CNS. J Neurochem 1999;72:879-882.
39. Cui J, Shao L, Young LT, Wang JF. Role of glutathione in neuroprotective effects of mood stabilizing drugs lithium and valproate. Neuroscience 2007;144:1447-1453.

40. Lai JS, Zhao C, Warsh JJ, Li PP. Cytoprotection by lithium and valproate varies between cell types and cellular stresses. Eur J Pharmacol 2006;539:18-26.

41. Chang YC, Rapoport SI, Rao JS. Chronic administration of mood stabilizers upregulates BDNF and bcl-2 expression levels in rat frontal cortex. Neurochem Res 2009;34:536-541.

42. Yasuda S, Liang MH, Marinova Z, Yahyavi A, Chuang DM. The mood stabilizers lithium and valproate selectively activate the promoter IV of brain-derived neurotrophic factor in neurons. Mol Psychiatry 2009; 14:51-59. 